\title{
Do pensamento clássico ao complexo na busca por justiça social: ensaio teórico
}

\author{
Juliana Berg ${ }^{1}$ \\ https://orcid.org/0000-0002-9729-7626 \\ Carla Luciane Blum Vestena ${ }^{2}$ \\ https://orcid.org/0000-0002-8655-7840 \\ Cristina Costa-Lobo ${ }^{3}$ \\ https://orcid.org/0000-0003-4459-8676
}

\section{Resumo}

O presente texto é resultado de pesquisa bibliográfica junto aos teóricos da complexidade, num esforço de tecer evidências, opinióes e posiçōes que possam ofertar oportunidade para a contraposição de ideias e o esclarecimento a respeito de nossas individualidades, práticas e da própria sociedade. Busca-se através desse, a ampliação da consciência relativa ao conviver e ao pensar cidadão diante da crise civilizatória, humanitária, sanitária, educacional e econômica que se vive. Como indicativo teórico final aponta para o pensamento complexo, por meio da transdisciplinaridade como meio educacional saudável promotor da ética humana, assim como, indica caminhos educacionais possíveis para "cidadania planetária” e justiça social, além de demonstrar ser o desenvolvimento humano por meio da criatividade a estratégia educacional mais atrativa e colaborativa no evoluir sistêmico da consciência respeitosa no viver.

Palavras-chave: Pensamento complexo, Pensamento clássico, Educação, Transdisciplinaridade, Justiça social

1 Bolsista CAPES, doutoranda em Educação pelo PPGE/Universidade Federal do Paraná. E-mail: bergjuliana@gmail.com.

${ }^{2}$ Bolsista produtividade da F.A.; Pesquisadora no Laboratório de Pesquisa Educacional - LAPE, Brasil; Docente Associada "A" da Universidade Estadual do Centro-Oeste, Brasil; Docente colaboradora do Programa de Pósgraduação em Educaçáo pela Universidade Federal do Paraná, Brasil. Pós-doutorado na School of Education, Durham University - UK. E-mail: cvestena@unicentro.br.

${ }^{3}$ Instituto de Estudos Superiores de Fafe, Cátedra UNESCO de Juventude, Educaçáo e Sociedade. E-mail: cristinalobo@iesfafe.pt. 


\section{From classical thinking to the complex and search for social justice: theoretical essay}

\section{Abstract}

This text is the result of bibliographic research with the theorists of complexity, in an effort to weave evidence, opinions and positions that can offer an opportunity for the opposition of ideas and the clarification about our individualities, practices and society itself. Through this, we seek to increase awareness of living and thinking about citizens in the face of the civilizing, humanitarian, health, educational and economic crisis that we are experiencing. As a final theoretical indication, it points to complex thinking, through transdisciplinarity as a healthy educational medium that promotes human ethics, as well as indicating possible educational paths for "planetary citizenship" and social justice, in addition to demonstrating that human development through creativity the most attractive and collaborative educational strategy in the systemic evolution of the respectful conscience in living.

Keywords: Complex thinking, Traditional thinking, Education, Transdisciplinarity, Social justice.

\section{Introduçáo}

Isolamento, egoísmo, alienação, irresponsabilidade, desrespeito ambiental, desequilíbrio ecológico, preconceitos, desastres naturais, ansiedade, violência, segregação, entre outros são males advindos de açôes/reaçốes há tempos. Então, por que agora parece que a dimensão desses fenômenos está amplificada? Será que perdemos o controle? Será que algum dia tivemos esse controle? Causamos tudo?

Segundo Morin (2012, p. 244), o futuro é imprevisível e indecifrável, assim é verdadeiro afirmar que nunca se esteve no controle, sendo a humanidade a causadora de tudo devido aos " [...] acontecimentos, inovaçóes, acidentes e descontroles locais capazes de desencadear açóes e reaçóes em cadeia, ou mesmo bifurcaçóes decisivas" que se amplificaram no decorrer do tempo, afetando a realidade e o futuro por alguns muitos anos. Mas, será que a humanidade tem consciência relativa aos danos, quando esses foram motivados por esperanças, metas e distopias?

Alguns teóricos e instituiçóes globais vêm na última década se preocupando com isso, estudando fenômenos como os mencionados e pesquisando o que parece evidenciar, principalmente em naçóes mais vulneráveis, serem respostas possíveis às tragédias ocorridas HUANG et al., 2020). Entretanto, sem cenários objetivos, o que vemos acontecer impressiona 
por sua natureza complexa e aponta, até o momento, para uma única certeza, principalmente sob perspectiva ambiental, a de que caminhamos para uma “[...] crise civilizatória e humanitária” sem precedentes (MORAES, 2019, p. 29)

Agora em 2020, ainda nesse ano, vivemos fenômeno incerto e triste que provoca crise em vários setores pelo desaceleramento brusco da rotina e morte em número exagerado de pessoas em todos os países. Trata-se da pandemia causada pelo Covid-19, que acrescentou ao que já era alarmante conflitos sanitários, educacionais e econômicos formatando essa como uma crise de dimensão local e global diferente de todas já vividas (HUANG Et al., 2020).

Segundo Berg, Vestena e Costa-Lobo (2020), os danos mais severos desta pandemia são de natureza social, sendo que na educação atingiram principalmente as crianças mais vulneráveis, deixando "[...] um rastro de violência intelectual e física difíceis de serem controlados” (p. 3), sendo necessária cautela e reflexão para agir e enfrentar o que ainda está por vir.

Damásio (2010) acredita que é por meio da consciência e do pensar que se consegue equalizar causas e efeitos, problemas e soluçóes, entretanto, parecemos sujeitos de consciência adormecida, com sensibilidade reduzida para o que significa a vida ou a importância da saúde, educação e meio ambiente.

De fato, sabe-se que a consciência não é um mero estado de vigília, possuindo falhas que limitam sua aplicação diante de paradigmas limitantes, essa nossa consciência pode até ignorar ou fingir não perceber o que de certa forma não nos interessa, mas ela não adormece. Hipoteticamente, na ausência dela:

[...] a visão pessoal suspende-se; não temos conhecimento da nossa existência; e não sabemos que existe mais alguma coisa. Se a consciência não se tivesse desenvolvido ao longo da evolução, expandindo-se até à sua versão humana, a Humanidade que agora nos é familiar, com todas as suas fragilidades e forças, também não se teria desenvolvido (DAMÁSIO, 2010, p. 21).

Para Damásio (2010), a cultura e a civilização não teriam surgido sem a consciência, portanto, "[...] gerir e proteger a vida de forma eficiente são duas proezas reconhecíveis da consciência” (p. 44) sendo o humano potencial 
agente desta gestão e proteção, devendo interferir e agir sobre tais fenômenos com justiça social.

Bem, mas essa não é uma discussão tão simplista, pois, sabemos que a humanidade consciente emerge na história, isso porque a consciência é "observada" podendo ser definida como um "[...] estado de alerta ou reconhecimento do eu e daquilo que o rodeia [...]" sendo "[...] estado mental a que foi acrescentado o processo do ser” (DAMÁSIO, 2010, p. 197). Assim, realizar a gestão da consciência é ação discutível e requer preparo, sensibilidade, respeito e consciência superior em educar para a convivência multidimensional, transdisciplinar e sistêmica, a qual náo exercemos atualmente, sendo urgente emergir consciência nova.

Entretanto, começar de novo não implica em perdoar falha histórica e não refletir sobre o pensamento moldado historicamente em meio paradigmático clássico, heteronormativo, patriarcal e branco pautado em exclusão. Erro e ilusão participam desse imaginário que vivemos. Pensar novo, por sugestão de Damásio (2010), implica em reconhecer nossa história e saber que ela

[...] tem a forma de uma árvore com inúmeros ramos, cada um levando a uma espécie diferente. Mesmo as espécies que não se encontram na extremidade de um ramo alto podem ser extremamente inteligentes no âmbito da sua vizinhança zoológica. As suas conquistas devem ser avaliadas em função dessa vizinhança. Mesmo assim, quando vemos a árvore da vida de longe, náo podemos deixar de reconhecer que os organismos evoluem do mais simples para o mais complexo (p. 349).

Assim, com a compreensáo de que vivemos localmente, mas o todo global impacta e atua em nossa consciência, devido a ordem e desordem que existe em todas as coisas vivas (MORIN, 2000), precisamos crer que não se derruba nossa árvore sem que os galhos fiquem no mesmo local sem movimento, assim como não se extrai os galhos sem que a árvore não sofra ou sinta-se atingida.

Portanto, ignorar a existência da história humana, da constituição de sua consciência e dos pensamentos que refletiram suas açóes é perda de tempo e de recursos. Assim como, a crise que assola vários cantos deste planeta nós humanos estamos em crise de consciência, sendo que o momento atual pede reflexão complexa e abandono de soluçóes simplistas e localizadas apenas em 
pensar as ferramentas ideias para se destruir o que é vivo - machado ou motosserra para árvore da vida-.

E nosso pensamento clássico há necessidade de dialógica para passagem à novo domínio conscienciológico de pensamento complexo advindo da valorização da educação, ciência e da natureza, de exemplos positivos, da análise, afeto, ética e autoconhecimento (MORIN, 2005a).

Nesse sentido, propóe-se neste texto em revisão bibliográfica, pensar, refletir e sentir a necessidade de mudança paradigmática que se apresenta. Para tanto, traz como subsídios referentes ao pensar clássico, cartesiano e em seguida apresenta base para o pensar complexo, apontando princípios e características de ambos.

Ao contrário do que se imagina, esse texto não tem pretensão de direcionar mudança, apenas pretende a reflexão ponderada e autocrítica do leitor, por isso, não traz conclusão, deixando-a em aberto. Assim, ao término, apresenta consideraçóes teóricas finais indicando possível caminho para transformar a realidade a partir de um lugar de fala nosso, advindo das áreas do conhecimento da Educação, Psicologia, Comunicação e das Ciências Humanas.

\section{Pensar Clássico}

A sociedade que vivemos é apoiada no ideal de humanidade racional que se sustenta no pensamento clássico, mantém na maioria das instituiçóes de ensino modelo de correção e eficiência mediante a quantificação de notas, currículo estruturado em conteúdos e áreas de conhecimento programáticas e tempo de aula específico que são, até certo ponto, simples e bem estruturadas para serem compreendidas quando se considera sua construçáo, mas injustas de serem pensadas se considerarmos o todo em que se contextualizam (MORIN; CIURANA; MOTTA, 2003).

A referida simplicidade é entendida como simplificação, não é intenção de subjugar, distante disso, trata-se apenas parte de entendimento para complexidade que coloca alguns princípios para seu estabelecimento. Reconhecer a simplificação é necessário, pois, a complexidade considera o obscurecer das "inter-relaçóes" existentes entre os fenômenos considerados universais e sobre os quais é preciso ver e lidar no mundo (MORAES, 2015). 
Simplificação, portanto, é um princípio para o pensamento clássico que busca pelo empirismo reducionista, promovido pela ideia de ciência fragmentadora e descontextualizada, baseada em laboratório. Assim, se sustenta no pensamento disjuntivo, aquele que separa e estuda em partes o que se pretende conhecer e pesquisar (MORAES, 2015).

Ocorre que ao se retirar objeto/pessoa/conteúdo de seu contexto de ação levanta-se cortina obscura que extinguem variáveis de inter-relação, capazes de alterarem a percepção e entendimento do que/quem se pretende pensar. Além disso, ao se eliminar tais inter-relaçôes, ou mesmo possiblidades de desvio por fator causal ao pensamento admite-se causalidade linear, unidirecional e processual, ou seja, causa eficiente para efeito observado, levando ao estabelecimento de conclusôes e "[...] leis cuja aplicação permitiu atingir o objeto e produzir efeitos de manipular os fenômenos" em coerência lógica, "homeostática", "[...] destinada a manter o equilíbrio do discurso mediante expulsão da contradição" (MORIN, 2005a, p. 82).

Concebe-se a partir disso, tentativa por um pensar programático, processual, linear, simplificado e estável que não admite contraditório ou inconvenientes, pois, uma vez localizado, diagnosticado e eliminado todo e qualquer fator causal, que na sociedade e escola podem ser de qualquer natureza, devido a diversidade das dimensôes atuantes nesses ambientes, torna-se possível predizer comportamentos e açóes para que sejam adotadas medidas regulatórias, planejamentos mecânicos e códigos de conduta com o objetivo de anular probabilidades futuras de erro, inconformidade ou inconveniente em detrimento ao que está programado.

É assim que a sociedade clássica busca manter o equilíbrio ou consenso esperado e adequado à função das instituiçóes que se concebem capazes de resultados, produtividade e eficiência de forma igualitária (MORIN, 2000).

Em suma, o pensamento clássico centra-se em ver, explicar, prever e classificar a ocorrência de fenômenos como desejáveis ou indesejáveis a determinada lógica estabelecida e regrá-los como meio para que não ocorram mais. Tal pressuposto de estabilidade gera ideal de controlabilidade e de eliminar turbulências à ordem que se explica ou explicada, não concebendo autonomia advinda de julgamento moral individualizado e contextualizado, considerado implícito e diverso ao permitido na manutenção do equilíbrio/controle coletivo pelo poder vigente (MORAES, 2015). 
É do exercício desse determinismo ambiental que o contexto clássico deriva, da ideia de previsibilidade, onde é possível o planejamento de "práticas instrutivas" necessárias para a manutenção da "ordem e do progresso", disciplinar com objetividade (VASCONCELLOS, 2002).

Houve, na sociedade clássica de origem cartesiana mesmo que inconscientemente, séculos de tentativa-erro na manutenção desse controle, isolando problemas que precisavam de tratamento e resolutividade, ignorando tragédias e fenômenos distantes das fronteiras que estivéssemos habitando, sem que a ordem imaginada como igualitária fosse alterada.

Esse desenvolvimento "disciplinar" manteve/mantem inconvenientes de superespecialização no enclausuramento do saber, "[...] constituindo-se grande desligamento das ciências da natureza", assim como, reduz significativamente a convivência em diversidade e o desenvolvimento da flexibilização das ideias (MORIN, 2005b, p.16).

O pensamento clássico passou a ser guiado por códigos de conduta para o conhecimento do ambiente de forma segura, altamente especializado em área ou disciplina específica (MORIN, 2005b). Porém, existem falhas em tal lógica homeostática que provavelmente foram as razôes de poder contestá-la, pois, quando consideramos fenômenos previsíveis, como imaginam os pensadores clássicos, devemos poder fazê-los a partir de observação, ou seja, esses precisam estar ao acesso do observador em contexto natural, para assim serem estudados (MORIN, 2005b).

Outra hipótese de falha é de que a partir desses pressupostos pensados como simplificadores, estáveis e objetivos se tenha gerado paradoxo no ideal de conhecimento e sociedade clássica, que ao longo dos tempos fez surgir inúmeros questionamentos relativos ao:

1. Se marginalizar inconvenientes sem procurar compreendê-los. Como fazemos com multidóes de usuários de craque em vários centros urbanos?

2. Desvalorizar a importância da diversidade sem aderi-la. Como se vê quando um país como o nosso, por exemplo, é eleito nação que mais violenta mulheres, maltrata idosos?

3. De murar, limitar e isolar contextos sem integrá-los. Como fazemos com nossas casas, escolas etc.?

4. Eliminar o caos sem entendê-lo e aprender com ele para superá-lo. Como estamos fazendo, negando a pandemia de Covid-19? 
5. De considerar normas igualitárias. Mesmo que as oportunidades não sejam equitativas?

6. E ignorar o que é subjetivo em nós? Sem integrá-lo a nosso corpo, que igualmente sente e vem sofrendo, apresentando na população mundial aumento da depressão e de suicídios?

Tal paradoxo é fruto do pensar clássico que age por exclusão. Tal exclusão sustenta forma de agir ou pensar em determinado contexto e tempo, mas, não conseguiu impedir o paradoxo de existir, isso porque há na ordem que tentamos controlar igual desordem operando desvio na rota estabelecida que induz a paradoxo, e essa desordem é de origem incerta, direcionamento imprevisível e dimensão não contabilizada (MORIN, 2005b).

Isso ocorre principalmente com o que é vivo, como nós. Porque ao inferir de forma coercitiva ação determinada ao sujeito, por toda complexidade que lhe é inerente (cultura/sociedade/meio ambiente/genética), há sempre alteração no processo de tomada de decisão, que provocada por sentimentos inconvenientes a quem determinou a regra/ordem procuram alternativas diferentes da imposta. Assim, na incerteza, o sujeito de ação coercitiva busca pela adaptação em outras soluçóes possíveis e paralelos contextuais, ou ainda, gera outras formas de ação que sustentem sua decisão em seu contexto natural/cultural/social de forma lógica individual promovida principalmente pelo egocentrismo que habita em nós.

Portanto, tal pensamento clássico cartesiano, por meio da “[...] soberania explicativa absoluta de ordem", tenta manter aparências advindas da manutenção da ignorância por meio da governança das "[...] unidades elementares de que é constituída (MORIN, 2005b, p. 331).

Tal imaginário tem, por exemplo, no "[...] progresso inédito dos conhecimentos científicos" advindos de pensamento clássico o "progresso múltiplo da ignorância"; no "progresso dos aspectos benéficos da ciência" o "progresso de seus aspectos nocivos ou mortíferos"; e no progresso ampliado dos poderes da ciência a "[...] impotência ampliada dos cientistas a respeito desses mesmos poderes" (MORIN, 2005b, p.18).

Exemplos dessa atividade paradoxal na vida cotidiana são os dilemas, como o relatado por Berry (2006, p. 59) sobre o que está acontecendo na agricultura, quando menciona que a "solução por métodos industriais que resolveram problemas relacionados com a produção de alimentos, chegaram 
acompanhados do que ele chamou de "efeitos colaterais" nocivos", a ponto de ameaçar a sobrevivência da própria agricultura e do ser humano que consome alimentos modificados por elementos químicos.

Ou ainda o dilema da criação do fast food como alternativa a qualidade de vida por otimização do tempo, que acabou por abreviar o mesmo tempo, por falta de qualidade de vida (WATERS, 2006).

Assim, está igualmente o paradoxo na educação clássica, que ao determinar sistema desenvolvido para garantir segurança, consenso e tranquilidade gerais passou a gerar evidente desconforto, violência e indisciplina. $\mathrm{Na}$ educação o que era mantido e/ou ignorado assumiu certo protagonismo promovendo o que na complexidade se chama de retroaçáo negativa. Nesse cenário, fenômenos caóticos e intersubjetivos eclodem em resposta a ação controladora imposta, o que leva o pensamento clássico ao questionamento por seus pensadores e pela própria ciência que o sustenta, que passou a perceber e se interessar pela existência da instabilidade e intersubjetividade nas formas de pensar para então aprender a conviver de forma mais consciente (MORIN, 2003).

Há, portanto, na sociedade contemporânea, ainda clássica, prerrogativa de que no conhecimento estão erro e ilusão. "O maior erro é subestimar o problema do erro; a maior ilusão seria subestimar o problema da ilusão" (MORIN, 2000. p. 19). Isso porque o conhecimento não retrata o mundo, é apenas a soma de percepçóes, palavras, ideias, teorias traduzidas e reconstruídas por meio do pensamento e da linguagem.

Quanto maior a perturbaçáo e os desejos que trazemos por determinados ideais, maior nosso risco ao erro e as decisóes que contemplam "pontos cegos", "[...] paralisia de paradigma ou doença fatal da certeza" (VASCONCELLOS, 2002, p. 33).

Assim, acredita-se que pelo paradigma de raiz cartesiana as percepçóes são influenciáveis e levam a tentativas orientadas, não-criativas, que acabam por tornarem-se inflexíveis e resistentes às mudanças, diante do desejo de se concretizar o idealizado. (VASCONCELLOS, 2002).

Segundo Morin (2000), tais características são capazes de imprinting cultural e força normalizadora, prejudiciais ao desenvolvimento intelectual e criatividade pela opressão de contributos culturais importantes na constituição do humano como a cultura familiar, religiosa e escolar do nível primário ao universitário. 
Nesse sentido, assim como a cegueira advinda de tal conformismo enraizado nessas instituiçôes sociais nas quais convivemos, uma certa seleção sociológica e cultural atua em nós, mesmo que de forma ilusória, pois, sem ela estaríamos vulneráveis ao incerto e em risco da perda de nossa verdade individual. Ocorre que para que possamos manter tal ideal de pensamento, como forma de imunizar nossa ideologia, buscamos território ideológico similar ao nosso conviver e fortalecemos o pensamento clássico validado por outros do mesmo grupo/instituiçáo (MORIN, 2000).

Esta é ação humana para dissociação dualista, seletiva e de natureza binária, fruto de todo paradigma cartesiano por meio do separar sujeito e objeto. Assim, tal ideia acaba atravessando outras áreas do conhecimento e gerando dualismo entre alma e corpo; qualidade e quantidade; espírito e matéria; finalidade e causalidade; sentimento e razão; liberdade e determinismo; existência e essência, entre outros mais fragmentados ainda como atribuição de estereótipos de natureza pejorativa como forma de sustentar nossa escolha por grupo ou classe de convivência diverso ao que se tem preconceito (MORIN, 2000).

Essa lógica burocrática constrói sociedade e povo tecnocrata que “[...] explode quando todos esses processos de racionalização irracional se tornam, mediata ou imediatamente, processos que conduzem à morte" (MORIN, 2005b, p.164).

Portanto, estamos realmente em crise civilizatória e humanitária com previu Moraes (2019) e precisamos caminhar para outro modo de pensamento voltado para uma cidadania planetária, um modo mais aberto e de consciência humana não artificial como estamos apostando futuramente.

O pensar clássico demonstra seus desgastes e promete entregar nossa decisão às inteligências artificiais como forma de gerar bem estar. Estamos prestes a entrar em novo paradoxo de inconformidade e risco, mas ainda náo criamos meios de lutar para que isso não ocorra. Por isso, refletindo sobre como pensamos atualmente, diante do que expusemos, podemos crer e apostar nesse bem estar idealizado? Fica um espaço para sua reflexão.

\section{Pensar Complexo}

Em cenário social, onde há prerrogativa do pensar sob vigilância, há inobservância do novo e do original, assim como de certas emoçóes em 
detrimento de outras. Por outro lado, onde há liberdade, emoção e as conexóes naturais provindas do existir corpo e mente são reconhecidas em toda sua diversidade, totalidade e singularidade há prevalência do pensar livre (MORIN, 2000).

No pensar complexo se considera o humano constituído no "[...] entrelaçamento do emocional com o racional”, assim enquanto a emoção fundamenta e libera, o racional cria coerência operacional dos "[...] sistemas argumentativos que construímos na linguagem, para defender ou justificar nossas ações” (MATURANA, 2002, p.18). Dessa forma, “[...] não há ação humana sem uma emoção que a estabeleça como tal e a torne possível como ato" (p.22).

Tal complexidade só poderá advir da consciência

[...] dos caprichos do comportamento humano advindo de uma acumulaçáo do conhecimento e da análise dos factos descobertos. Dedicar tempo a analisar factos, a avaliar o resultado de decisôes e a ponderar os desenlaces emocionais dessas decisóes é o melhor caminho a tomar para construir sabedoria. Com base nessa sabedoria podemos deliberar e ter a esperança de orientar o nosso comportamento de acordo com a estrutura das convençóes culturais e das regras éticas que formaram a nossa biografia e o mundo em enfrentar o conflito que é desencadeado quando discordamos delas, e até mesmo tentar modificálas (DAMÁSIO, 2010, p. 345).

Segundo pensamento complexo, acredita-se que é preciso pensar "novo-paradigmático" onde há seleção do que está aderido ao discurso e a teoria "ou posto de lado, rejeitado" para que haja clareza de que no paradigma reside ordenamento lógico capaz de atribuir validade e universalidade a lógica adotada, axiomas, conceitos, discursos e/ou teorias, portanto, há necessidade de junção do que estava separado (MORIN, 2000, p. 25).

Reside em tal dilema o devir da sociedade contemporânea, que precisa tentar sob matriz programática, diante da incerteza do conhecimento manter a produção de ideias capazes de desenvolver o conhecimento do conhecimento, pois, segundo princípios de complexidade as pessoas devem procurar desenvolver consciência pela procura da verdade através de "metapontos de vista", da reflexão, da integração "observadorconceptualizador" em nosso contexto mental e cultural, sem esquecer que 
precisa ao mesmo tempo "instaurar a convivialidade, tanto com ideias, quanto com fantasias, erros e cegueiras” (MORIN, 2000, p.27).

Nesse sentido, pesquisadores devem promover a civilização de conceitos e criar nova geração de pesquisas e estudos com "[...] teorias abertas, racionais, críticas, reflexivas, autocríticas e aptas a se auto-reformar" ( MORIN, 2005a, p.30), onde criatividade e pensamento crítico são fundamentais para o surgimento de um "princípio de explicar mais rico" do que o da simplificação (p.32).

Isso é possível, entretanto o acesso parece restrito às pessoas que estão fora da área do controle clássico, ou pouco influenciadas pelas velhas ideias que alimentam capacidade filosófica e a dúvida como prerrogativa para autoquestionamento, auto-organização de ideias e pensamentos e que consideram a perda como parte do processo de criação e regeneração de seu pensar.

Há, portanto, nesses "quens complexus", certa propensão ao risco e coragem, desenvolvidos para que continuamente haja e adquiram "condição de existência e possibilidades de resistência em seu viver/conviver cotidianos" (MORAES, 2015, p. 67).

Neles, a percepção voltada para o saber especializado é mantida, porém, em concordância com habilidade e talento individuais que precisam serem respeitados e saírem do anonimato sem que percam a percepção do todo e do global, pois, contextualizar a ideia ao problema como solução é saber que tal prática advém da reflexão clássica, segregada e não complexa (MORIN, 2000).

Segundo Morin (2000), a sociedade para o futuro deve ser universal, "[...] centrada na condição humana" e no "[...] remembramento dos conhecimentos oriundos das ciências naturais", pois, "devemos reconhecer nosso duplo enraizamento no cosmos físico e na esfera viva” (p.47).

Trata-se de uma concepçáo de pensamento ecossistêmico, onde ambientes de aprendizagem, como espaços de convivência se configuram auto-eco-reorganizadores e relacionais, vivos e criativos por meio de interaçóes biopsicossociais entre alunos, professores, família, representantes comunitários, recursos e demais tecnologias digitais. Um espaço de aprendizagem num exercício de solidariedade e colaboração (MORAES, 2009). 
Trata-se de pensamento que não nos permite o abandono do sujeito, mas sim, pressupóe a presença de mim e do outro, onde ambos "estão implicados e co-determinados em sua materialidade física existencial" (MORAES, 2010, p. 78).

Segundo Moraes (2009), a chave da complexidade está em compreender ou em reconhecer a uniáo da simplificação e da complexidade e entender o movimento recíproco inerente a ela.

Nesse sentido a concepção de realidade, sob pensamento complexo é a de ser

[...]multidimensional em sua natureza interdependente, mutável, entrelaçada pelos fluxos que acontecem no ambiente e a partir do que cada um faz. Uma realidade que é contínua, descontínua, indeterminada em sua dinâmica operacional, que se manifesta dependendo do contexto, das situaçóes vividas e das circunstâncias criadas. O reconhecimento da existência de múltiplas realidades a legitimidade de todas elas é algo muito importante para essa construção teórica (MORAES, 2009, p.77;78).

Nessa realidade a vida precisa de tempo para encontrar seu devir, é preciso tempo igualmente na educação para escuta sensível e para que a percepção conecte os conhecimentos à localidade e globalidade da vida, tempo para processar as informaçóes.

Tal compreensão de temporalidade é importante, principalmente no que tange a sociedade, que precisa mais do que nunca, "[...] estar a serviço da aprendizagem e não apenas em função dos aspectos burocráticos, políticos, rotineiros e patriarcais predominantes" (MORAES, 2010, p. 83).

A cultura é outro aspecto importante na concepção de um homem para o pensar complexo, uma vez que sua realização plena se dá pela e na cultura (MORIN, 2000). Para Morin a cultura é “[...] conjunto de hábitos, costumes, práticas, savoir-faire, saberes, normas, interditos, estratégias, crenças, ideias, valores, mitos que se perpetua" (2007, p.35) entre geraçóes, sendo organizada pela sociedade, que também é responsável pelo "[...] capital cognitivo coletivo dos conhecimentos adquiridos, das competências aprendidas, das experiências vividas, da memória histórica, das crenças míticas” (MORIN, 2002. p.19).

Nesse caminho, segundo Petraglia e Gonçalves (2012), 
Apostando na emancipação por meio do conhecimento, Morin explicita sua concepção de hibridismo cultural, que concerne à admissão de uma abertura cultural com a perspectiva de ampliação do acesso aos saberes universais, o que permite que se tenha mais autonomia e liberdade (p.40).

Portanto, o pensar bem implica em tempo para contemplação, pois, assim e a partir de uma “[...] concepção ampliada de conhecimento - que inclui a decodificação de informaçóes pelo domínio do vivo em geral -, podemos falar de três níveis de conhecimento" essenciais, sendo: os sistemas vivos; o meio ambiente natural; e "[...] a escala de afastamento maior em relação aos objetos que pretende conhecer, dos quais fala, aos quais imputa sentido e edifica interpretaçóes" (ALMEIDA, 2008, p.132).

Segundo Suanno (2015), igualmente é necessária outra cosmovisão que não a de domínio e da conquista da natureza. É preciso respeito, cuidado e proteção sendo preciso antes abraçar novas ideias concebidas pela autora como princípios de vida responsável e da ética planetária como um contrato possível de ser feito na sala de aula.

Para Nicolescu (2005) a viabilidade da sociedade e do pensar complexo só é alcançada se for integral do ser humano, de totalidade aberta e que ajude a construir pessoas questionadoras que busquem constantemente integração.

Assim, ambientes passam a ser espaços de vivência e de configuração de identidades e construção de cidadania, de aprendizagem da corporeidade, onde o "uso de imagens, sons, músicas, situaçóes para sentipensar, provocadoras de setipensamentos agradáveis, criativos e positivos" provocam o surgimento de ecoambientes propícios aos debates saudáveis e construtivos em ética local e planetária (MORAES; TORRE, 2005, p.63).

Estratégias que segundo Torre (2009), eliminem: a fragmentação dos saberes; a perda de visão de conjunto; o academicismo dominante; a clara petrificação sem desafios; conhecimentos descontextualizados da realidade e da vida; generalizada desmotivação; ansiedade; alarmante crescimento da violência na vida social e a contaminação, além da degradação do meio ambiente.

Nesse sentido, é da educação a responsabilidade pela transição de pensamento clássico para complexo. Segundo Antunes de Sá (2015), uma pedagogia para complexidade é pautada pelo “[...] método de pensar complexo que é compreendido um caminho, uma estratégia para se chegar a 
um conhecimento pertinente" (p.65), ela parte de um olhar que "capture as tramas, os dramas, os fios e os nós do processo educativo, ou seja a organização escolar passa a ser percebida em uma perspectiva sistêmico-organizacional" (p.66).

Assume destaque, portanto, a capacidade/ habilidade/ aptidão natural para: curiosidade; flexionar ideias; o experienciar erros e dificuldades, assim como suas soluçóes; deve-se desenvolver a partir do questionamento o pensamento crítico e identificação da falsa racionalidade, tanto própria quanto sutilmente imposta ou dominante (ALMEIDA, 2017).

Nisso se sustenta a importância do entendimento educacional e valorização da/para diversidade, pois, "[...] compreender o humano é compreender sua unidade na diversidade, sua diversidade na unidade". Tratase de unidade/diversidade genética, cerebral, mental, psicológica, afetiva, intelectual, subjetiva etc., além de igualmente social, linguística, organizacional e cultural (MORIN, 2000, p.56).

\section{Consideraçóes finais}

Somos: duais e antagônicos; racionais e afetivos; do mito e do delírio; do trabalho e do lúdico; empíricos e criativos; infantis, neuróticos, delirantes e racionais. Essa é a humanidade. Portanto, a sociedade para o hoje e adiante terá a vocaçáo para o questionamento e para o pensar complexo com humanidade para fins de tomada de decisão em pensamento crítico e criatividade.

Aprender e pensar é processo progressivo, contínuo de convivência que dura a vida, "[...] todo tempo e de maneira recíproca" entre criança e adultos em comunidade. Trata-se de sistema que "[...] configura um mundo" e as crianças "[...] confirmam em seu viver o mundo que viveram em sua educação” (MATURANA, 2002, p.29).

Assim, onde se vive o educar como um devir de modo que a criança aprenda a "[...] aceitar-se e respeitar-se, ao ser aceita e respeitada em seu ser se constrói o pensar complexo" (MATURANA, 2002, p.32).

Nesse sentido, se há algo para aprendermos agora é o estar aqui no planeta. "[...] aprender a viver, a dividir, a comunicar, a comungar. É o que se aprende somente nas e por meio de culturas singulares" e terrenas (MORIN, 2000, p. 76). 
Assim, devemos desenvolver consciência antropológica; ecológica; cívica; espiritual; criativa/destrutiva; e (auto) crítica (MORAES, 2019). Moraes e Batalloso (2015) acreditam que sabe-se da crise da civilização atual, que é igualmente crise ética e que "[...] trouxe consigo o enfraquecimento da responsabilidade e da solidariedade”, desfazendo relaçóes humanas e aniquilando dispositivos "[...] produtores de sentido como a educação, religião, a ética, a arte, entre outros” (p. 143).

Sabe-se igualmente, que ética é de natureza transdisciplinar, uma vez que "perpassa toda ação, ou processo educacional transversalmente", sendo todo seu processo educativo fundamentado e relacionado com "valores e neles não existem lugar para a neutralidade” (MORAES; BATALLOSO, 2015, p.147).

Segundo Moraes (2019, p.146), falamos de pessoas que se fazem de forma social, política, comunitária, mas que também se fazem sensíveis, afetivos, participativos, compreensivos, empáticos e que refletem sobre suas experiências. Sendo assim, tal contexto pede humano integrado em sua complexidade e para isso são necessárias escolas que caminhem para evolução transdisciplinar, que segundo Nicolescu (2005) "tem no prefixo trans em indicação àquilo que está ao mesmo tempo entre áreas do conhecimento através" (p.08).

Segundo Moraes (2015), para integrar as principais dimensóes constitutivas de uma visão transdisciplinar social é preciso saber que ambas estão fortemente vinculadas, mediante diferentes tipos de relaçóes, as quais constituem matriz de onde devem partir possíveis indicadores capazes de descrever a sociedade nas dimensóes: ecossocial e planetária; psicofísica, corporal, emocional e cognitiva; dimensão criativa e estética; e dimensão política.

Nesse sentido, o conhecimento transdisciplinar assume ideário de tessitura complexa, dialógica e autoeco-organizadora expressando continuidade e cada vez maior aprofundamento (RIBEIRO; MORAES, 2014).

Segundo Ribeiro; Moraes (2014, p. 247), sob tal perspectiva a criatividade aparece, mesmo que de forma não aparente, reconhecida como "[...] fenômeno de natureza complexa e transdisciplinar" fruto de tessitura objeto/sujeito/processo. Nesse sentido, como afirma Moraes 
[...] a criatividade é emergente porque sua presença - ou a capacidade de dar respostas novas aos velhos problemas que podem também ser repensados de um novo modo - depende da presença de flexibilidade pessoal e estrutural, de adaptação a novos ambientes (2005, p. 123).

Zwierewicz (2013) indica como uma das possiblidades para dinamizar essa perspectiva os Projetos Criativos Ecoformadores (PCE). Sua prática tem sido difundida por meio de várias intençôes implícitas e explícitas de desenvolvimento, por pretenderem se tornar uma via metodológica para educação desde e em direção ao pensamento complexo.

$\mathrm{Na}$ prática, todo PCE inicia por epítome que ancora teoria e prática, ciência e realidade, seus valores, problemas e avanços. Além dessa, outras açóes estratégicas são admitidas como forma de sistematização do projeto: legitimação teórica e pragmática; perguntas geradoras; metas; eixos norteadores; itinerários; coordenadas temporais; avaliação emergente; polinização - fecundação de projeto em outros entornos -; reflexôes para seguir adiante.

A criatividade pode auxiliar nisso, nesses projetos de natureza complexa, uma vez que "[...] sua multidimensionalidade exige flexibilidade estrutural de pensante, de ação de fluência cognitiva, espiritual, psicológica" ao inferir sobre objeto ou ao vivenciar determinadas situaçóes (MORAES, 2015, p.171). Ela pode contribuir com a sociedade de várias formas, especialmente na experiência vivenciada, nas sensações, na percepção do outro, na ressignificação do momento, repensando espaços, processos, produtos, sujeitos e no autoconhecimento. Trata-se de um estado de consciência sistêmica e transdisciplinar onde há plenitude interna com prevalência e reconhecimento de dinâmica operacional, onde as intuiçóes e o imaginário proporcionam campo energético informacional e comunicativo que auxilia no estabelecimento de elo orgânico entre a realidade interior, a zona de resistência e a realidade exterior oportunizando maior justiça social.

\section{Referências}

ALMEIDA, Leandro. Criatividade e Pensamento Crítico. In: ALMEIDA, Leandro. Criatividade e Pensamento Crítico: avaliação e desenvolvimento. Braga: Centro de Estudos e Recursos em Psicologia, 2017. p.5-17. 
ALMEIDA, Maria de Conceição; PETRAGLIA, Izabel. Estudos de Complexidade. São Paulo: Xamã, 2008.

ANTUNES DE SÁ, Ricardo. Em busca de uma Pedagogia Complexa. In: BEHRENS, Marilda Aparecida; ENS Romilda Teodora. Complexidade e Transdisciplinaridade: novas perspectivas teóricas e práticas para a formação de professores. Curitiba: Appris, 2015. p. 61-74.

BERG, Juliana; VESTENA, Carla Luciane Blum; COSTA-LOBO, Cristina. Criatividade e Autonomia em Tempo de Pandemia: Ensaio Teórico a partir da Pedagogia Social. Revista Internacional de Educacion para la Justicia Social, n. 9 , v. 3e, 2020. p. 1-17. Disponível em: https://revistas.uam.es/riejs/article/view/12180 . Acesso em: 05 de nov.2020. BERRY, Wendell. A solução pelo padrão. In: STONE, Michael; BARLOW, Zenobia. Alfabetização Ecológica: A educação das crianças para um mundo sustentável. São Paulo: Cultrix, 2006. p.58-68.

DAMÁSIO, Antonio. O Livro da Consciência: a construção do cérebro consciente. Maia: Círculo de Leitores, 2010.

HUANG, Rongui H. et al. Handbook on facilitating flexible learning during educational disruption: The chinese experience in maintaining undisrupted learning in covid-19 outbreak. Institute of Beijing Normal University, 2020.

MATURANA, Humberto. Emoções e Linguagem na Educação e na Política. Belo Horizonte: Editora UFMG, 2002.

MORAES, Maria Cândida. Perspectivas do pensamento ecossistêmico e suas implicaçóes nos ambientes de ensino e aprendizagem. In: ALMEIDA, Maria de Conceição; PETRAGLIA, Izabel Estudos de Complexidade 3. São Paulo: Xamã, 2009, p.99-122.

MORAES, Maria Cândida. Complexidade e currículo: uma relação necessária. Estudos de Complexidade 4. São Paulo: Xamã, 2010.

MORAES, Maria Cândida. Transdisciplinaridade, criatividade e educação: Fundamentos ontológicos e epistemológicos. Campinas: Papirus, 2015.

MORAES, Maria Cândida. Saberes para uma Cidadania Planetária: homenagem a Edgar Morin. Rio de Janeiro: Wak Editora, 2019. 
MORAES, Maria Cândida; BATALOSSO, Juan Miguel. Um olhar complexo e transdisciplinar sobre ética e educação. In: BEHRENS, Marilda Aparecida; ENS Romilda Teodora. Complexidade e Transdisciplinaridade: novas perspectivas teóricas e práticas para a formação de professores. Curitiba: Appris, 2015. p. 143-174.

MORAES, Maria Cândida; TORRE, Saturnino De La. Fundamentos del Sentipensar. In: TORRE, Saturnino De La; MORAES, Maria Cândida. SENTIPENSAR: Fundamentos y estrategias para reencantar la educación. Málaga: Ediciones Aljibe, 2005. p.63-85

MORIN, Edgar. Os sete saberes necessários à educação do futuro. Brasília: UNESCO, 2000.

MORIN, Edgar. O Método 4: As ideias, habitat, vida, costumes, organização. Porto Alegre: Sulina, 2002.

MORIN, Edgar. A Cabeça Bem-Feita: repensar a reforma - repensar o pensamento. Rio de Janeiro: Bertrand Brasil, 2003.

MORIN, Edgar. Introdução ao Pensamento Complexo. Porto Alegre: Sulina, 2005a.

MORIN, Edgar. Ciência com Consciência. Rio de Janeiro: Bertrand, 2005b.

MORIN, Edgar. O Método 5: A humanidade da Humanidade e a identidade humana. Porto Alegre: Sulina, 2012.

MORIN, Edgar; CIURANA, Emilio; MOTTA, Raul Domingos. Educar na Era Planetária: o pensamento complexo como método de aprendizagem no erro e na incerteza humana. São Paulo: Cortez Editora, 2003.

NICOLESCU, Barsarab. Transdisciplinarity: past, present and future. In: Congresso Mundial de Transdisciplinaridade, Vila Velha/Vitória, 2005.

PETRAGLIA, Izabel; GONÇALVES, Natália. Cultura, Identidade e Educação. In: ALMEIDA, Maria de Conceição; PETRAGLIA, Izabel. Estudos de Complexidade 5. São Paulo: Xamã, 2012, p.39-50.

RIBEIRO Olzeni; MORAES, Maria Cândida. Criatividade em uma perspectiva transdisciplinar: rompendo crenças, mitos e concepçóes. Brasília: Liber Livro, 2014. 
SUANNO, Marilza. Vanessa Rosa. Educar em prol da Macrotransição: emerge uma didática complexa e transdisciplinar. In: EHRENS, Marilda Aparecida; ENS Romilda Teodora. Complexidade e Transdisciplinaridade: novas perspectivas teóricas e práticas para a formação de professores. Curitiba: Appris, 2015. p.199-214.

VASCONCELLOS, Maria José Esteves de. Pensamento Sistêmico: o novo paradigma da ciência. Campinas, SP. Papiros, 2002.

WATERS, Alice Os valores da fast food e os valores da slow food. In: STONE, Michael; BARLOW, Zenobia. Alfabetização Ecológica: A educação das crianças para um mundo sustentável. São Paulo: Cultrix, 2006. p.77-83.

ZWIEREWICZ, Marlene. Projetos Criativos e Ecoformadores - PCE: inovação metodológica e estímulo à transdisciplinaridade no ensino superior, In: ZWIEREWICZ, Marlene. Criatividade e Inovação no Ensino Superior: experiências latino-americanas e europeias em foco. Florianópolis: Nova Letra Editora, 2013.

Recebido em: 01 ago. 2020

Aceito em: 20 ago. 2020 